\title{
INEQUALITY AT THE TOP. THE GENDER WAGE GAP AMONG THE ITALIAN EDUCATIONAL ELITES
}

\author{
GIAMPIERO PASSARETTA ${ }^{\mathrm{a}^{*}} \quad$ MORIS TRIVENTI $^{\mathrm{b}}$ \\ ${ }^{a}$ European University Institute, Department of Political and Social Sciences \\ ${ }^{\mathrm{b}}$ University of Trento, Department of Sociology \\ *Corresponding author: giampiero.passaretta@eui.eu \\ Discussion Paper
}

\begin{abstract}
Women notoriously get lower wages compared to men. Does a gender wage gap exist also at the top of the educational distribution? Based on population data on two recent cohort of $\mathrm{PhD}$ graduates in Italy, we found women's monthly wages are on average 16\% lower than men's' after 5-6 years on the labor market. The gender wage gap is even stronger at the very bottom and the top of the wage distribution, around $22 \%$ and $19 \%$ respectively. Educational pathways before and during PhD studies, occupational characteristics, and the family situation explain almost half of the average women's penalty and working hours alone one-fifth of it. However, the strongest penalties at the bottom and the top of the wage distribution remain largely unexplained.
\end{abstract}

Keywords: Gender wage gap, doctoral graduates, discrimination, wage inequality, $\mathrm{PhD}$

Acknowledgments: Giampiero Passaretta acknowledges funding from the European Union's Horizon 2020 research and innovation program under grant agreement No. 822330 (TECHNEQUALITY). We are grateful to Fabrizio Bernardi, Raffaele Grotti and all other participants of the first Distant CLIC (Comparative Life Course and Inequality Research Centre) seminar at the European University Institute for constructive comments and discussion. 


\section{INTRODUCTION}

The gender wage gap (GWG, hereafter) is a ubiquitous phenomenon: despite the promotion of equal-pay opportunities legislation, women earn less than men in virtually all Western societies (Blau \& Kahn 2017). This basic fact stimulated fierce scholar and public debates. The existence of a gender wage gap challenges the view of a fair and efficient job allocation process in Western economies. In terms of equity, modern economies are believed to rely on meritocratic principles of functioning and to reward workers according to productivity and not ascriptive characteristics, such as gender or race (Treiman 1970). In terms of efficiency, the existence of the GWG represents a disincentive for women's productivity and future generations of women to invest in education and human capital.

Scholars have long been interested in the drivers of the GWG (Mandel 2016) and analyzed its variations across countries, time and subgroups of the population (Arulampalam et al. 2007; Bertrand et al 2010; Boll et al 2017). A crucial attempt in the existing literature was to distinguish the raw difference between the average wages of men and women - the raw GWG - from the component that is purely due to statistical or taste discrimination against women (Di Prete \& Buchmann 2006). Recent research has shown that the raw GWG has decreased in the last decades (Iceland \& Redstone 2020), albeit being still substantial in recent times (Blau \& Kahn 2006; 2017). Other studies found substantial gender gaps also among tertiary graduates, both in the US (Joy 2003) and Europe (Garcia-Aracil 2009; Triventi 2013). Finally, some studies in the US have already begun to investigate the GWG among the educational elite, that is $\mathrm{PhD}$ degree holders, and showed that even in this selected subgroup of the population women tend to earn less than men (Torche 2018).

This article focuses on recent cohorts of doctoral degree holders in Italy and contributes to the literature on the gender pay gap in contemporary societies by providing a better understanding of the sources of disadvantages faced by highly educated women in the labour market. Albeit $\mathrm{PhD}$ holders are a group relatively small in size, the attention on their occupational outcomes is crucial for several reasons. First, at a macro level, doctoral graduates play a key role in fostering economic development and promoting innovation in knowledgebased societies (Garcia-Quevedo et al. 2012; Diamond et al 2014). PhDs represent "educational elites" who are likely to enter the most prestigious and remunerative occupations in the labour market and contribute to growing economic inequality (Posselt \& Grodsky 2017). Second, at 
the micro-level, it is important to understand whether unequal pays persist even among the individuals with the highest level of human capital and for which competence should be the fundamental criterion of recruitment and promotion (Hout 1988). This is especially relevant nowadays as women have surpassed men in university graduation and academic performance (Di Prete \& Buchmann 2006). Third, it is interesting to understand whether a GWG still exists in a selected segment of the population with allegedly strong preferences towards employment (Hakim 1977). Finally, since wages are comparatively higher among doctoral graduates than among lower educated individuals, gender wage penalties sum-up to a particularly large amount throughout the employment career (Goldan 2020).

This study is organised around two main objectives. The first aim is to unclose the existence of a GWG among recent cohorts of $\mathrm{PhD}$ graduates in Italy. The second aim is to quantify the importance of a variety of individuals' characteristics related to educational pathways, occupational careers, and family situations in explaining the GWG. A key contribution of the paper is to move beyond average differences in the wages of men and women. We do so by exploring whether the GWG differs along the wage distribution and examining which factors are more important in driving the observed GWG in the lower and the upper tails.

The empirical analysis makes use of population data from two recent cohorts of $\mathrm{PhD}$ graduates for which we have rich information on the educational careers and the occupational outcomes 5-6 years after doctoral degree attainment. By relying on high-quality population data, we improve on the few existing contributions in the literature that relied on local samples of $\mathrm{PhD}$ graduates and touched the issue of gender disparities only tangentially (e.g. Ballarino and Colombo 2010; Lee et al. 2010; Campostrini 2011; D’Agostino and Ghellini 2011).

We show that women get lower wages compared to men even at the top of the educational distribution in Italy. Women's penalty is $16 \%$ on average and even higher at the bottom and the top of the wage distribution. What is more, the stronger gender gaps in the tails remain vastly unexplained by individual characteristics featured in widespread narratives on the roots of the GWG in contemporary societies. 


\section{THEORETICAL FRAMEWORK}

\section{EXPECTATIONS ON THE GWG AT THE MEAN}

The literature on gender inequalities in the labour market, and especially on pay gaps, distinguishes demand and supply side explanations for females' penalties. Supply side explanations stress the role of gender differences in preferences for education, occupation, family arrangements and in structural and cultural constraints related to gender norms (Gin et al. 1996; Gash 2008; Hakim 1997). Demand side explanations, instead, stress the role of employers' prejudices and statistical discrimination when recruiting prospective employees, negotiating their wages, and deciding about tasks assignments and promotions.

The concept of selection is key when focusing on the subgroup of the population at the top of the educational distribution. The selectivity of the PhDs matters for both demand and supply side explanations. On the supply side, it is important to bear in mind that $\mathrm{PhD}$ graduates are only a small portion of their birth cohort and had successfully survived educational transitions of increasing difficulty (Mare 1981). This especially relevant in Italy, where educational attainment lags behind the OECD average and the proportion of $\mathrm{PhD}$ holders among the population aged 25-44 is comparatively low, approximately 0.5\% (OECD 2019). Hence, it is likely that $\mathrm{PhDs}$ differ to the average individual in many respects, for example in terms of cognitive and non-cognitive skills, attitudes and preferences towards employment. This could be particularly true for women. One may speculate that $\mathrm{PhDs}$ are more attached to the labour market than the individuals with lower educational attainment and such educational gradient may be stronger among women than men. Thus, female PhDs are likely to value their occupational career over family responsibilities and to find partners inclined to share familyrelated duties that helps work-family reconciliation.

Selection is also important for demand side explanations. Labour market is segmented and graduates compete for specific types of occupation (Beck et al. 1978; Leontaridi 1996). Some authors highlighted that recruitment criteria in labor markets for tertiary graduates are mostly inspired by meritocratic principles (Hout, 1988). According to this perspective, employers screen potential candidates for high-skilled positions mostly based on educational qualifications and ability rather than ascriptive characteristics, such as gender or social background (Breen, 2004; Breen \& Jonsson, 2005). These arguments would lead us to expect a reduced or even no GWG among $\mathrm{PhD}$ graduates. Yet, the few existing international studies portrait a different story. In the $\mathrm{UK}$, female $\mathrm{PhDs}$ earn $11 \%$ lower wages compared to men 
after 3 years and a half on the labor market (Schulze (2015). This figure amounts to $16 \%$ in Sweden (Amilon and Persson 2013) and 17\% in recent US cohorts (Rathnasekara, 2019). A number of studies in Germany found a GWG ranging from 16\% (Goldan 2019) to even 46\% (Bornmann and Enders 2004) depending on the specific cohort and especially time after $\mathrm{PhD}$ considered. In the early 2000s, a study conducted on a selected sample of $\mathrm{PhD}$ holders in Northern Italy reported a GWG of around 200 euros per month (Ballarino and Colombo 2010).

It is also important to consider the broader cultural, economic and institutional context in which our $\mathrm{PhD}$ cohorts made the transition to the labour market. Some of the cohorts examined in this work entered employment in a period of economic instability and hiring stagnation (Passaretta, Triventi \& Trivellato 2019). In times of economic downturns firms are less inclined to hire new personnel or more likely hire workers on a temporary basis (Kahn 2010), a pattern that could even be more pronounced among the vulnerable categories of job seekers, such as women. Moreover, Italy is a country where traditional gender norms survived modernization and still impair women's attachment to the labor market, especially in the South. Hence, even if equally productive compared to men, women at the top of the educational distribution in Italy may discount labor market attachment due to personal preferences or the anticipation of discriminatory practices even in high-skilled segments of the economy.

All in all, the findings in other countries and the considerations on the institutional, cultural and broader economic context in Italy lead us to expect a GWG even among the strongly selected population of $\mathrm{PhDs}$, although not dramatic.

\section{EXPECTATIONS ON THE GWG ALONG THE DISTRIBUTION}

The previous studies on the general population suggest stronger gaps at the top or the bottom of the wage distribution (e.g. Arulampalam et al. 2006). There is also evidence that variations along the wage distribution depend on the educational level examined. In Spain, for example, the GWG grows along the wage distribution for the tertiary educated but widens towards the bottom for the lowest educated (De la Rica, Dolado and Llorens 2005).

The economic literature investigated distributional dynamics of the GWG and particularly to the component of women's disadvantage that cannot be traced back to observed individuals' characteristics. Such unexplained component is traditionally assumed to measure discrimination against women. The stronger discrimination at the top and at the bottom found in many studies were labelled 'glass ceiling' and 'sticky floors', respectively (Booth et al. 2003; 
Cohen \& Huffman 2007; Bjerk 2008; Christofides et al. 2013). A "glass ceiling" refers to a hidden barrier that excludes women from being hired and promoted in top positions, for example, barriers to highly remunerated positions in executive rankings, such as directors and corporate officers. In contrast, a 'sticky floor' represents a situation where women, despite having similar endowments compared to men, have less chances to climb up the ladder and are trapped for longer time in low paid entry-level positions (Booth et al. 2003).

The interpretation of variations of the unexplained GWG along the wage distribution as a "glass ceiling" or a "sticky floor" rests on the assumption that the unexplained gap reflects discriminatory behaviour only. Such assumption is violated by construction in many of the previous studies since the unexplained gap also reflects non-perfect accounts of all potentially relevant individual characteristics impacting wages. This work makes no exception and, therefore, we interpret with caution variations of the unexplained GWG along the wage distribution. We rather focus on whether larger raw GWG in the tails of the distribution can be found also among $\mathrm{PhD}$ holders in Italy.

All in all, we expect the GWG to be stronger in the tails of the wage distribution, according to some of the previous studies focused on the general population. Such pattern should also hold for the portion of female's penalty not related to individuals' characteristics and perhaps reflecting discriminatory behaviour more closely.

\section{FACTORS EXPLAINING THE GWG}

The raw GWG is the result of multifaceted process entailing individuals' endowments (supply side) and employers' discriminatory practices (demand side). In the literature, supply side drivers usually classify into four main groups: human capital factors, occupational features, working time and family-responsibilities (e.g. Triventi 2013). Differences in the distribution of a given endowment can contribute to explain the GWG if such endowment boosts economic returns and, at the same time, less often characterizes women compared to men. We now discuss whether and how several sets of endowments can plausibly contribute to account or the GWG among PhD holders. At the end, we also underly the importance of some demand side factors entailing employers' discriminatory behaviour. However, it is important to recognize that access to a given endowment, such as educational credentials or the sector of employment, is the result of individual preferences but also depends on the broader set of opportunities and constraints faced by individuals in their life course. The access to a give endowment may even 
reflect anticipation of future employers' discriminatory behaviour. Hence, while analytically useful, the theoretical distinction between supply and demand factors is not as sharp as some of the previous studies have assumed so far.

\section{HUMAN CAPITAL FACTORS}

$\mathrm{PhD}$ holders achieved the highest level of education possible and represent a country educational elite. Notwithstanding, PhDs differ for a variety of characteristics that may represent additional qualifying elements for the labour market, both in terms of productivityenhancing skills and indirect signals of productivity and trainability. These may include characteristics of pre-doctoral educational careers (e.g. grades, track attended in high school), characteristics of the $\mathrm{PhD}$ program (access to grant, region, field of study) and the experiences accumulated during doctoral studies (e.g. teaching, visiting periods abroad). While all these factors plausibly relate to wages in- and outside academia, strong gender disproportions in the endowment of those factors is rather unlikely. It is even likely that those factors are at the advantage of women: females usually perform better in school (Buchmann, DiPrete, \& McDaniel 2008) and inequalities in higher education have been declining and even reversing in recent times (Jacobs 1998).

Among human capital factors we deem the field of study as perhaps the most important. Men are disproportionally represented in engineering, maths and computer science at the tertiary level, while women disproportionally represented in education, humanities and the social sciences, a pattern found in Italy (Triventi 2010) and elsewhere (Charles and Bradley, 2002; Barone 2008). It is also widely known that technical and scientific fields lead to more remunerated occupations than humanistic degrees and the social sciences in many countries (Reimer et al. 2008; Ballarino \& Bratti 2009). According to these arguments, the previous research indicates the field of study as an important driver of the GWG among tertiary graduates (Gerber and Cheung, 2008), even if its contribution appears to be reduced when controlling for individuals' general skills and more detailed individual characteristics (Triventi 2013).

\section{OCCUPATION FACTORS}

The second set of factors includes occupation-related characteristics, such as the worker's experience, type of occupation and contract, workplace and sector of employment. Among the 
labour market factors, the existing literature highlights the role of occupations and occupational sectors (Charles and Grusky 2004; Mandel and Semyonov 2006; Mandel 2012; Olivetti \& Petrongolo 2008; Smyth \& Steinmetz 2008) as women concentrate in occupations and sectors characterized by lower pay (Leicht 2008), less career mobility, and less working autonomy and authority (Reskin 1993; Chang 2000). The previous studies reported significant gender differences in the occupational destinations of PhDs in many countries: Women are less likely to work in occupations related to management and hard sciences while being more likely to work in occupations related to the social sciences (ESF 2015).

Occupational segregation contributes to the GWG through two main mechanisms (Petersen \& Morgan 1995): first, discrimination in recruitment and promotion procedures (allocative discrimination); second, lower salaries associated with female-dominated occupations (valuative discrimination). Allocative discrimination could be the results of individual choices but also discrimination in hiring, as employers prefer men for maledominated jobs and women for female-dominated jobs on the basis of prejudice (Reskin and Roos, 1990), the expected risk of losing female workers due to motherhood (England, 2005), statistical discrimination (Bielby and Baron, 1986) or in the attempt to preserve the status of a job by keeping women out (Goldin, 2002). Valuative discrimination may occur because female-dominated occupations are considered less important for societies (devaluation thesis; England, 1992), characterized by less occupation-specific training (Tam, 1997) and oversupply (crowding thesis; Bergmann, 1974).

It is also crucial to consider the workplace and in particular in the country of work, as there is clear evidence that the Italian $\mathrm{PhDs}$ working abroad benefit a wage premium (Di Cintio \& Grassi 2017). Moreover, female PhDs in Italy are less likely to work in a foreign country five years after doctoral graduation (Passaretta et al. 2019), a pattern that is possibly linked to family or caring commitments and other work-life balance issues (Ackers and Gill 2008; Børing et al 2015).

\section{WORKING HOURS AND FAMILY SITUATION}

Working hours merit particular attention among supply-side factors. Many of the existing studies on the GWG focus on the average hourly wage, thus factoring out working hours and obscuring a fundamental part of the processes that generate the actual women's penalty. Moreover, the average hourly wage rate is less appropriate to analyze the GWG among 
professionals, since their returns to working hours seem non-linear (Arthur \& Morgan 2005). Studies focused on the general population found that women are more likely to be employed in part-time or reduced-time jobs, and this in turn affects their monthly earnings (Kunze 2015). The literature suggests that working time is influenced by both individual preferences (Hakim, 1997) and external constraints that limit the opportunities available to women (Ginn et al., 1996), including family and care responsibilities, which are usually considered a central additional explanatory factor for the GWG (Blossfeld et al. 2015). Differences in working time are not only rooted in labor market processes but might also stem from individual preferences produced by gendered processes of socialization, experiences in the education system, informal peer pressure and family duties (Fagan, 2001) as well as anticipation of subsequent discriminatory behavior on the labor market.

When thinking about the importance of working hours for the GWG among $\mathrm{PhD}$ graduates it is important to consider two aspects. On the one hand, the selectivity of the population under scrutiny brings us to hypothesize that working hours may be more balanced between men and women with a PhD compared to the general population. On the other hand, 'non-linear contracts' in high-skilled professional occupations might put women at a disadvantage. Men are more likely than women to work in occupations and occupational sectors where additional working hours are disproportionately rewarded, a situation Goldin (2014) refers to as a non-linear wage-hours schedule. If this is the case, then working hours should be particularly important in explaining the GWG at the top of the wage distribution.

The fourth set of supply-side explanations refers to the compatibility between employment with gender-differentiated family roles. Albeit some improvements in the genderbalance over time, women still do the majority of household work and are usually responsible for childcare, whereas men hold primary responsibility for the financial viability of the family (Crompton and Lyonette 2006). Reconciling employment and family obligations is also strictly intertwined with individual aspirations. Albeit women may discount paid work for family formation and duties (Halaby 2003), it is likely that gender differences in the attitudes towards employment and the family are comparatively limited among $\mathrm{PhD}$ holders.

\section{EMPLOYERS' DISCRIMINATION}

At the end, it is important to consider supply side explanations for the GWG. Supply side explanations refer to discriminatory processes in the labour market, that is a situation where 
men and women with analogous endowments and employed in the same occupation receive a different salary from the same employer. Employers' hiring and promotion decisions might be driven not only by considerations of profit maximization but also by 'taste discrimination' (Becker 1971) or 'statistical discrimination' (Phelps 1972). In this perspective, employers' (or their customers') decisions can be guided by prejudices against women or stereotyped information based on the productivity characteristics of women as a group. Unfortunately, like most of the previous studies, we are not in the position to identify precisely the contribution of discriminatory practices to the GWG but rather focus on the role of endowments in explaining women's wage penalty. At the same time, we should keep in mind that the role of endowments may also capture discriminatory practices, at least to some extent.

\section{ANALYTICAL STRATEGY}

\section{DATA}

We use unique and high-quality population data from two rounds of the 'ISTAT Survey on Italian PhD Graduates' conducted in 2009 and 2014. The data includes information on two cohorts of PhDs graduated in 2004 and 2008 and interviewed 5-6 years after graduation (in 2009 and 2014 respectively). All $\mathrm{PhDs}$ graduated were invited for the interview with no exceptions. Data were collected via CATI in 2009 and via CAWI in 2014. Response rates were above $70 \%$ in both rounds, which is far beyond the response rate of other commonly used data. Regardless of the extremely high response rate, we used adjustment factors provided in the surveys to ensure that our analyses are fully representative of the $\mathrm{PhD}$ cohorts. Details on the adjustment weights provided by the surveys are available in the Supplementary material (Section A). The sample includes 13,577 individuals overall and $98 \%$ of such sample was nonmissing on our analytical covariates (see Table 1). Among the latter sample, $95 \%$ were employed at the moment of the interview and $85 \%$ of the employed reported the monthly wage. Our final analytical sample includes 10,682 PhDs across the whole spectrum of academic disciplines: 5,158 graduated in 2004 and 5,524 in 2008

\section{[TABLE 1]}




\section{MONTHLY WAGES}

We use the monthly wage to evaluate individuals' position in the stratification of economic resources. Alternative measures, such as hourly wages, are closer measures of individuals' productivity and earning potential but may not reflect the actual availability of economic resources. Women's working schedules are often subject to constraints that go beyond individual preferences and, therefore, the time devoted to paid labour is an important driver and a crucial theoretical dimension when it comes to the explanation of gender wage gap.

Information on the exact monthly wage was self-reported and missing in approximately $15 \%$ of the cases in our analytical sample (see Table 1). Missingness was equally likely among men and women in both rounds. Regardless of the balance between men and women, we adopted a weighting strategy to account for selective missingness on wages based on gender, $\mathrm{PhD}$ cohort, place of work, social origin, field of study, and region of $\mathrm{PhD}$ attainment, separately in the two surveys. Adjustment factors were computed using inverse probability weighting and trimmed via response propensity score stratification (Chen, Gelman, Tracy, Norris, \& Galea, 2012; Seaman \& White, 2013). In short, our procedure assigned higher weights to individuals with higher probability of having not reported their wages and, at the same time, avoided biases due to extreme adjustment factors resulting from imperfect weighting models. Technical details on the weighting procedure are in the Supplementary material (section A).

Information on wages was released for scientific use after truncation of the tails. Wages were truncated in approximately $4 \%$ of the cases in our analytical sample. Therefore, we can rely on exact information for almost all individuals. ${ }^{1}$ The proportion of truncated wages is similar among men and women. Among men, the proportion of subject in the upper truncated tail is higher than women's ( $1.9 \%$ vs $0.9 \%)$, while the opposite is true for the truncated lower tail (1.9\% of men and 3.4\% of women). Such slight differences suggest that, if anything, our analyses provide a conservative estimate of the gender wage gap at the mean. Under the assumption that men's exact wages are more likely in the upper values of the truncated tails,

\footnotetext{
${ }^{1}$ Truncation mostly occurred in lower tail of the distribution, where the variance in true wages is mechanically limited by zero. Hence, truncation likely has a minor impact the estimated mean GWG. Furthermore, truncated wages are out of the quantile range examined, thus they do not affect the estimates from the distributional analysis.
} 
also the gender gap at the top and bottom of the wage distribution is likely an underestimation of the true gap. Additional information on truncation is in Supplementary table B1.

Monthly wages are weighted by the purchasing power of the country of work ( $\mathrm{PhDs}$ may work outside Italy) and the reference year (2009 or 2014) and then logged to obtain an approximately normal distribution. The log-transformation preserves the variance and allow us interpreting the gender wage gap as percentage difference between the wages of women compared to men. ${ }^{2}$ Before the log-transformation, the average monthly wage in our analytical sample is 1,529 Euro; the $10^{\text {th }}$ and $90^{\text {th }}$ percentiles are 888 and 2,336 Euros, respectively.

\section{CONTROL VARIABLES AND ENDOWMENTS}

Table 2 lists the covariates used in the analyses. Missingness on those covariates was minor in the data, less than $2 \%$ (see Table 1). The first set of variables controls for potential composition of our sample in terms of cohort of graduation, social origin, and citizenship.

The second set groups the remaining endowments, that are the supply side drivers of the GWG, into five categories. First of all, we distinguish two groups of human capital factors: Pre-PhD characteristics, including information on the previous educational histories, such as high school track and grades; and PhD-studies characteristics, including a vast array of features of the $\mathrm{PhD}$ attained, such as the 14 detailed fields of study at the doctoral level, the timing of completion, and the teaching experience, among others.

\section{[TABLE 2]}

The third group of endowments includes occupational features such as the contract type and whether the job is framed within a formal profession or carried out abroad. Unfortunately, detailed occupational codes were not available in the data. However, we were able to include a detailed variable distinguishing 25 sectors of the economy. Such a variable also distinguishes research jobs in- and outside academia as well as the detailed positions in academia, which are

\footnotetext{
${ }^{2}$ Truncation does not allow us to use alternative relative measures of the gap such as differences in the percentile wage ranks. In any case, percentile ranks would yield a substantial loss of information as they express gender gaps in a variance-free metric.
} 
by far the largest sector of employment for $\mathrm{PhDs}$ in Italy (around 37\% of $\mathrm{PhDs}$ in our sample were employed in academia).

Working hours are considered in a left-alone category because, as we discussed earlier, they may be particularly important in explaining the gender wage gap in Italy. The last group of factors includes some variables related to the family situation, such as the civil status and the presence of children.

\section{METHODS}

The analyses revolve around two main objectives. First, to establish the existence of a GWG. Second, to explain the gender gap by several PhDs' characteristics. The raw gender wage gap at the mean - that is the difference in the average logged wages of men and women - is virtually identical to the conditional gap once controlled for the socio-demographic characteristics listed in Table 2 (see Supplementary figure $\mathrm{C} 1$ ). Hence, for the sake of simplicity and parsimony, we focus on the estimation and the decomposition of the raw gender gap only.

In the first part of the analyses, we use OLS and quantile regression to estimate the raw GWG at the mean and along deciles of the unconditional distribution of the (log)wages. Unlike other studies focused on the general population (e.g. Kunze 2015), selectivity into employment is a minor issue in out context. Table 1 shows that $95 \%$ of our $\mathrm{PhDs}$ were employed at the moment of interview and, therefore, our estimates are representative of the vast majority of the population under scrutiny. As a sensitivity check, we also accounted for selection bias in the estimation of the average gender gap via Heckman selection models and found similar results (see Supplementary figure $\mathrm{C} 1){ }^{3}$

In a second step, we apply Kitagawa-Oaxaca-Blinder (KOB, hereafter) decomposition methods (Jann 2008) to assess the overall percentage of the gender gap explained by PhDs' characteristics (the endowments) and the specific role of the various $\mathrm{PhDs}$ ' characteristics in accounting for the gender gap at the mean and along the distribution of wages. While the decomposition of the average gender gap requires standard tool of analyses, the decomposition

\footnotetext{
${ }^{3}$ According to common a common practice in labour economics, we use the number of children and the civil status as exclusionary restrictions in the two-steps estimation.
} 
along the wage distribution is more challenging. The KOB method implies the identification of the unexplained (residual) part of the gender-wage association when feeding covariates into the model (the endowments in our specific case). The problem arises from the fact that, unlike in bivariate quantile regression, coefficients for the residual gender gap cannot be interpreted as the average differences between the wages of men and women at different quantiles of the unconditional distribution of wages. Indeed, individuals at the high end of the distribution of wages conditional on covariates are not necessarily those who are actually at the high end of the unconditional wage distribution. A standard solution to approximate the interpretation of coefficients from conditional quantile regressions to the bivariate scenario is unconditional quantile regression (UQR) (Firpo, Fortin, \& Lemieux, 2009). UQR consists in regressing transformations of the outcome - the recentered influence functions (RIFs) - rather than unconditional quantiles themselves on the covariates of interest. A similar use of RIFs also extends to decomposition methods, such as Kitagawa-Blinder-Oaxaca, as shown in Firpo, Fortin, \& Lemieux (2007). Such approach allows us to apply KOB decomposition to distributional statistics and decompose the gender gap at different deciles of the unconditional distribution of wages. In particular, we estimate the contribution of both the broad categories of endowments (pre-PhD characteristics, $\mathrm{PhD}$ characteristics, occupational features, working hours, family situation) and all detailed variables therein in accounting for the raw gender wage gap. To estimate this model we relied on the-oaxaca_rif - routine in the Stata statistical software (Rios-Avila 2020).

It is important to bear in mind that the decomposition analysis, both in the classical KOB method and in the RIFs approach, assesses the contribution of each endowment to the GWG by relying on a shift-share analysis that simulates how the GWG (at the mean or at specific quantiles) would look like if a given characteristic (e.g. field of study) was distributed similarly among men and women. While this approach does not allow for a 'micro-individual' interpretation of the effect of the endowments, it is relevant from a policy perspective as it identifies the factors on which policy interventions have the highest potential to reduce gender wage inequality. 


\section{EMPIRICAL RESULTS}

\section{IS THERE A GENDER WAGE GAP AMONG PHDS?}

Figure 1 plots the raw gender wage gap expressed in percentage differences in women's wages compared to men at the mean (orange line) and along the unconditional wage distribution (connected black lines). On average, the women's monthly wage is around 16\% lower than men's. This figure is astounding if we consider that we are picturing a portrait of the Italian educational elite, which is likely a more homogeneous group in terms of occupational aspirations and ability compared to the general population. As anticipated, the average gender gap remains unchanged when adjusting for potential differences in the composition of doctoral graduates in terms of socio-demographic characteristics and accounting for sample selection bias (see Supplementary figure $\mathrm{C} 1$ ). The existence of an average gap between male and female $\mathrm{PhD}$ holders is consistent with our general expectation and the previous findings in other national contexts (Amilon \& Persson 2013; Goldan 2019; Rathnasekara 2019; Schulze 2015; Torche 2018).

The average gender gap masks important dynamics along the wage distribution as women's penalty is more pronounced in the tails. Women's wages are $22 \%$ lower compared to men at the bottom decile of the wage distribution. Instead, the gender penalty between the $20^{\text {th }}$ and the $70^{\text {th }}$ percentiles is slightly lower than the average figure (11-14\%) and around 19\% among earners above the $80^{\text {th }}$ percentile. Overall, population data for the two cohorts of $\mathrm{PhD}$ graduates support a U-shaped pattern featuring stronger gender inequality at the top and the bottom of the wage distribution. Such a pattern resembles some of the previous international research that found stronger gaps in the tails of the wage distribution when looking at the general population (Arulampalam et al. 2006) or tertiary graduates in particular (De la Rica, Dolado \& Llorens 2005).

\section{[FIGURE 1]}

\section{EXPLAINING THE GENDER WAGE GAP}

Figure 2 shows the overall contribution of the five groups of endowments (pre- $\mathrm{PhD}$ and $\mathrm{PhD}$ characteristics, occupational characteristics, working hours, and the family situation) to the 
explanation of the GWG. Panel A shows the percentages of the total GWG explained at the mean (orange line) and along the wage distribution (black connected lines) computed as ratios between the explained components and the raw gaps estimated via KOB decomposition. Panel B, instead, shows the raw GWG on the log-scale and the relative explained and unexplained components along the distribution. Altogether, our endowments explain approximately $42 \%$ of the average difference among the wages of men and women (see panel A). However, this figure changes strikingly when looking at different points of the wage distribution. Indeed, the explanatory power of the observed endowments is highest between the $20^{\text {th }}$ and the $40^{\text {th }}$ percentiles, where endowments explain between half and $70 \%$ of women's penalty. Conversely, endowments explain only around $27-30 \%$ of women's penalties in the high portion of the wage distribution (from the $80^{\text {th }}$ to the $90^{\text {th }}$ percentile) and at the very bottom (10 ${ }^{\text {th }}$ percentile).

\section{[FIGURE 2]}

Panel B visualizes the portion of the raw GWG (in log-points) that remains unexplained by endowments. The figure clearly shows that the unexplained component is markedly stronger in the tails (where the raw gap is highest). Hence, it seems that classical individual characteristics used to explain women's penalties on average are increasingly inadequate when it comes to account for the stronger penalties we observed in the tails. This result is consistent with some of the previous studies that found evidence for either "sticky floors" or "glass ceilings" in different countries and subgroups of the population. Our results on $\mathrm{PhDs}$ graduates in Italy are consistent with both dynamics, although we are unable to rule out artefacts due to imperfect measurement that may artificially inflate the unexplained component. This is a limitation we share with all the previous studies.

But which are the most important factors when it comes to the explanation of women's disadvantage? We start by reporting results from the decomposition of the average gender wage gap (Figure 3). Panel A reports the contribution of pre- $\mathrm{PhD}$ and $\mathrm{PhD}$ characteristics, occupational characteristics, working hours, and the family situation to the average gender gap. Panel B details the specific contribution of each of the factors included in the five categories of endowments. Altogether, the contribution of the five broad categories sums up to $42 \%$. Also 
note that the contribution of the detailed categories within a broad category sums to the overall contribution of the broad category.

The figure clearly shows that the lion's share of the average difference in men's and women's wages is explained by characteristics of the occupation obtained after the $\mathrm{PhD}$ attainment and the working hours, in line with our expectations. Around $20 \%$ of the average gender gap roots in occupational differentiation in terms of contract type, place of work, detailed sector of employment, timing of the job entry, and professional orientation of the job (see Panel A). This figure implies that men took advantage of occupational differentiation. If women had the same distribution of occupational characteristics men have, the gender wage gap would be lower by approximately $20 \%$. Among the occupational characteristics, the contract type and especially working abroad are the most important factors and explain around 6 and $10 \%$ of the women's penalty respectively (see Panel B). Men are much more likely to have a permanent contract ( 8 percentage points) and to work abroad ( 4 percentage points) compared to women, and these two occupational characteristics come with large wage gains among our PhD cohorts (see Supplementary table B2). It is interesting to see that the detailed sector of employment does not explain a large share of women's penalty: while there are strong differences in the average wage by sector, female $\mathrm{PhDs}$ do not systematically segregate in those occupational sectors with the lowest economic returns (see Supplementary table B2). Finally, according to our theoretical speculations, working hours are of particular importance and explain $22 \%$ of the average gap alone.

[FIGURE 3]

Contrary to our expectations, $\mathrm{PhD}$ characteristics seem to play a minor role and altogether account for approximately $5 \%$ of women's penalty. This is almost entirely due to differentiation in terms of the field of study at the $\mathrm{PhD}$ level, which explains $4 \%$ of the GWG alone. While the role of the field of study is non-trivial, it is lower than we expected based on the notion that men traditionally graduate from more remunerative fields at the tertiary level. In our $\mathrm{PhD}$ cohorts, men were more likely to graduate from hard sciences characterised by larger monetary returns, such industrial engineering, mathematics and physics (see supplementary table B2). However, the share of women graduated from other remunerative 
fields, such as in law and economics, is similar to men and even one-third higher in the most remunerative field, which is medicine (see Supplementary table B2).

It is also striking that both characteristics of the educational career prior to $\mathrm{PhD}$ enrolment and especially family arrangements explain a minor portion of the average gender gap. The negative values of -1.8 implies that the average gap would be only $1.8 \%$ lower if men had similar family arrangements than women (see Panel A). However, we should bear in mind that our study is genuinely limited when it comes to the assessment of the role of family arrangements, as we were in the position of including only a few indicators for the family situation. In absence of additional information, the role of the family situation may have been picked up by the number of hours worked on a monthly basis in our decomposition analyses. It is likely that the extraordinary role played by working hours in our analyses also reflects the gender imbalance in care obligations and the division of labour at home, at least to some extent.

Finally, it is interesting to examine whether characteristics of the educational and occupational careers and the family situation are of different importance in explaining the gender gap at various points of the wage distribution. We have already shown that our five groups of endowments are better suited to explain women's penalty in the middle-low portion of the distribution of wages, while being less suited to explain why men's get higher wages at both the top and the bottom. Are some specific groups of mediators more important than others when it comes to explain the gender inequality in the tails? Figure 4 provides a generally negative answer to this question. The most important characteristics, that are those related to the occupation, are better suited to explain the gap between the $20^{\text {th }}$ and $40^{\text {th }}$ percentile, and so do characteristics of the doctoral studies. Working hours, instead, seem equally important for the explanation of women's penalty throughout. Finally, the decomposition of the gender gap along the wage distribution confirms the residual importance of family arrangements and characteristics of the educational career prior to doctoral enrolment. Additional analyses (not shown) indicate that the role of the detailed categories for the explanation of the average gap does not vary dramatically when we shift the focus to the bottom and top deciles of the wage distribution.

[FIGURE 4] 


\section{CONCLUSIONS}

The gender gap in wages is a highly debated phenomenon in advanced economies. Most of the current research focuses on gender differences looking at the whole population in general or tertiary graduates in particular. Only a few studies have investigated gender inequalities in early occupational outcomes among individuals with the highest educational attainment, namely doctoral graduates. By drawing a portrait of an elite segment in the Italian labour force, the article offered new insights into processes of labour market inequality for a population that is widely believed to have meritocratic opportunities. In particular, we examined whether women obtain lower wages compared to men five to six years after $\mathrm{PhD}$ graduation, both on average and along the wage distribution. Also, we examined to extent to which the GWG traces back to gender imbalances in the distribution of human capital factors, occupation characteristics, working time and family responsibilities.

A substantial GWG exists even among recent cohorts of $\mathrm{PhD}$ graduates in Italy despite the high level of selectivity of the population under scrutiny. Women earn on average $16 \%$ less than men, a result closely in line with recent findings from United States (Rathnasekara 2019), Germany (Goldan 2019), and Sweden (Amilon and Persson 2013). In Italy, this amount translates into an estimated gap of approximately 260 Euros per month, which in turn leads to an annual difference of 3,129 Euros. Albeit this could appear not excessively large, it is important to bear in mind three aspects. First, wages are lower in Italy compared to other countries and 260 Euros per month represent a substantial amount. Second, the GWG in this work refers to men and women who are equally highly qualified and specialized. Third, we focused on wages five years after $\mathrm{PhD}$ graduation, but there is evidence of increasing female penalties along the occupational career (Weichselbaumer \& Winter-Ebmer 2005).

The wide array of individual characteristics we considered explains less than half of the GWG at the mean, up and even more than two-third in the middle-lower part of the wage distribution and only around one-third in the tails. The unexplained GWG is strikingly largest in the tails, a pattern that is coherent with the arguments on the existence of both 'sticky floors' and 'glass ceiling' phenomena in academia and in high-skilled segments of the labour market. Yet, it is difficult to attribute the unexplained part of the GWG solely to discrimination processes since it could also be due to unmeasured individual characteristics (or measurement error in the observed variables). For example, a recent work found that $14 \%$ of the unexplained GWG is due to a lower willingness to commute by women, who are less likely to move far 
away from home to find a job (Le Barbanchon, Rathelot \& Roulet 2020), a factor that has been rarely considered in previous works. Absence of information on this factor artificially inflates the unexplained component and, when the unexplained component is attributable uncritically to discriminatory practices, also overestimates discrimination against women. We are in favour of a prudential interpretation and limit ourselves to the observation that traditional predictors of wage appear of weak importance when it comes to explain why women's penalty is strongest in the tails of the wage distribution. The evidence is consistent with the idea that discretionary hiring and promotion decisions on the employers' side, individuals' attitudes and preferences, and other individuals factors we were not able to measure matter more for the explanation of the GWG in the tails of the wage distribution rather than middle or on average. Further research is needed to better quantify the extent of discriminatory processes and to distinguish those discriminatory processes from the influence of other unmeasured individual characteristics.

The were some notable exception to our expectations. In line with previous studies on tertiary graduates (Garcia-Aracil 2009; Triventi 2011), human capital factors seem not crucial when it comes to explain the average GWG. All in all, it seems difficult to attribute the women's penalty to their allegedly lower level of skills and qualifications. Interestingly, also the field of study explains a relatively small fraction of the GWG. Albeit women and men tend to enrol in different fields of study also at the doctoral level, women are not overly segregated in those fields that systematically lead to lower-paid jobs. For instance, women access and graduation from Medicine grew over time and is even higher among women than men in recent cohorts (Triventi 2010).

Occupational destinations play a crucial role in explaining the GWG. Only some specific job characteristics appear to make the difference, however. The most important aspects are working abroad and the type of contract, while occupational sectors does not contribute significantly to explain women's penalties. Women are more likely to be employed with a temporary contract and, differently from other countries, access to fixed-term contracts also entail a wage penalty in Italy. In the same vein, men are more likely to work abroad and such a decision entails high economic return.

The contribution of both human capital and occupational factors for the explanation of the GWG is stronger in the middle-low part of the wage distribution. This result is consistent with the idea that men disproportionally avoid overeducation and access specific segments of the labour market that protect them from receiving very low wages. Along with more classical 
indicators of labour market position, weekly working hours seems to be of critical importance for the explanation of gender differences in monthly wages. Notably, its contribution is rather constant along the wage distribution, thus not providing support for non-linear wage-hours schedules among Italian $\mathrm{PhD}$ graduates (Goldin 2014).

In sum, our results imply that the GWG among the educational elite is primarily driven by differentiation in terms of where (abroad), how long (hours), and under which conditions (contract type) men and women do for a living after the $\mathrm{PhD}$ attainment. Despite the selectivity of the population under scrutiny, key factors that are relevant in the whole population appear to be important also among doctoral degree holders, for instance working hours. Whether differences in time invested on the job are the result of external barriers or individual preferences and choices is an issue that deserves further investigation. In conclusion, it seems that the selectivity of female $\mathrm{PhD}$ holders in terms of ability and attitudes toward employment does not spare those women from conditioning and obstacles in a society still characterized by rather traditional gender norms and unequal labour market opportunities. 
TABLES AND FIGURES

Table 1. Definition of the analytical sample.

\begin{tabular}{ll}
\hline & $\mathrm{N}$ \\
\hline Overall & 13,557 \\
Non-missing on covariates & 13,324 \\
Employed & 12,621 \\
Non-missing on wages (analytical sample) & 10,682 \\
$\quad$ PhD cohort 2004 (survey 2009) & 5,158 \\
PhD cohort 2008 (survey 2014) & 5,524 \\
\hline
\end{tabular}


Table 2. Overview of covariates used in the analyses.

\begin{tabular}{|c|c|c|c|c|c|}
\hline \multirow{3}{*}{$\begin{array}{l}\text { Parental education } \\
\text { Citizenship } \\
\text { PhD cohort }\end{array}$} & \multicolumn{5}{|c|}{ ENDOWMENTS (supply side drivers) } \\
\hline & Pre-PhD ${ }^{b}$ & PhD studies ${ }^{c}$ & Occupation $^{\mathrm{d}}$ & $\begin{array}{l}\text { Working } \\
\text { hours }\end{array}$ & Family situation $^{\mathrm{e}}$ \\
\hline & $\begin{array}{l}\text { High school track } \\
\text { High school grade } \\
\text { Graduation abroad }\end{array}$ & $\begin{array}{l}\text { Field of study } \\
\text { Age at completion } \\
\text { Delay } \\
\text { Teaching experience } \\
\text { Grant } \\
\text { Visiting abroad } \\
\text { Macro-region }\end{array}$ & $\begin{array}{l}\text { Detailed sector } \\
\text { Professional job } \\
\text { Contract type } \\
\text { Job start } \\
\text { Work abroad }\end{array}$ & $\begin{array}{l}\text { Weekly } \\
\text { hours }\end{array}$ & $\begin{array}{l}\text { Civil status } \\
\text { Children }\end{array}$ \\
\hline
\end{tabular}

Notes: ${ }^{a}$ Parental education: Both primary or less, one lower secondary, one upper secondary, both upper secondary, one tertiary, both tertiary; Citizenship: Italian/other; PhD cohort: 2004 vs 2008. ${ }^{\mathrm{b}}$ High school track: Liceo classico, liceo scientifico, liceo linguistico, liceo sociopsicopedagogico, liceo artistico, istituto tecnico, istituto professionale, foreign institution. High school grade: 110 or less, 110 or more. Graduation abroad: Yes/no. ${ }^{c}$ Field of study: All fourteen fields of study available at the PhD level. Age at completion: 29 or less/35 or more. Delay: Yes/no. Teaching experience: Never, occasionally, regularly. Grant: standard, 'assegno di ricerca', teaching grant, none. Visiting abroad: Yes/no. Macro-region: North-east, nort-west, centre, south. ${ }^{\mathrm{d}}$ Detailed sector: Agriculture, mineral extraction, energy, water and waste management, chemical and pharmaceutical products, machinery and mechanical equipment, electtical, elettronic and optical equipment, transportation equipment, other industries, academia: professors, academia: tenured researchers, academia: non-teanured researchers, academia: administration and technicians, academia: other, non-academic instruction, research: public, research: private, public administration and defence, professional, scientific and technical activities, health and care, finance and insurance, information and communication, commerce, accomodation, and restoration, international organizations, transport services, other services, human resources. Professional job: Yes/no. Contract type: standard, non-standard, self-employment. Job start: before/after PhD. Work abroad: Yes/no. ${ }^{\mathrm{e}}$ Civil status: single, married/cohabitating, widowed/divorced. Children: Yes/no. 


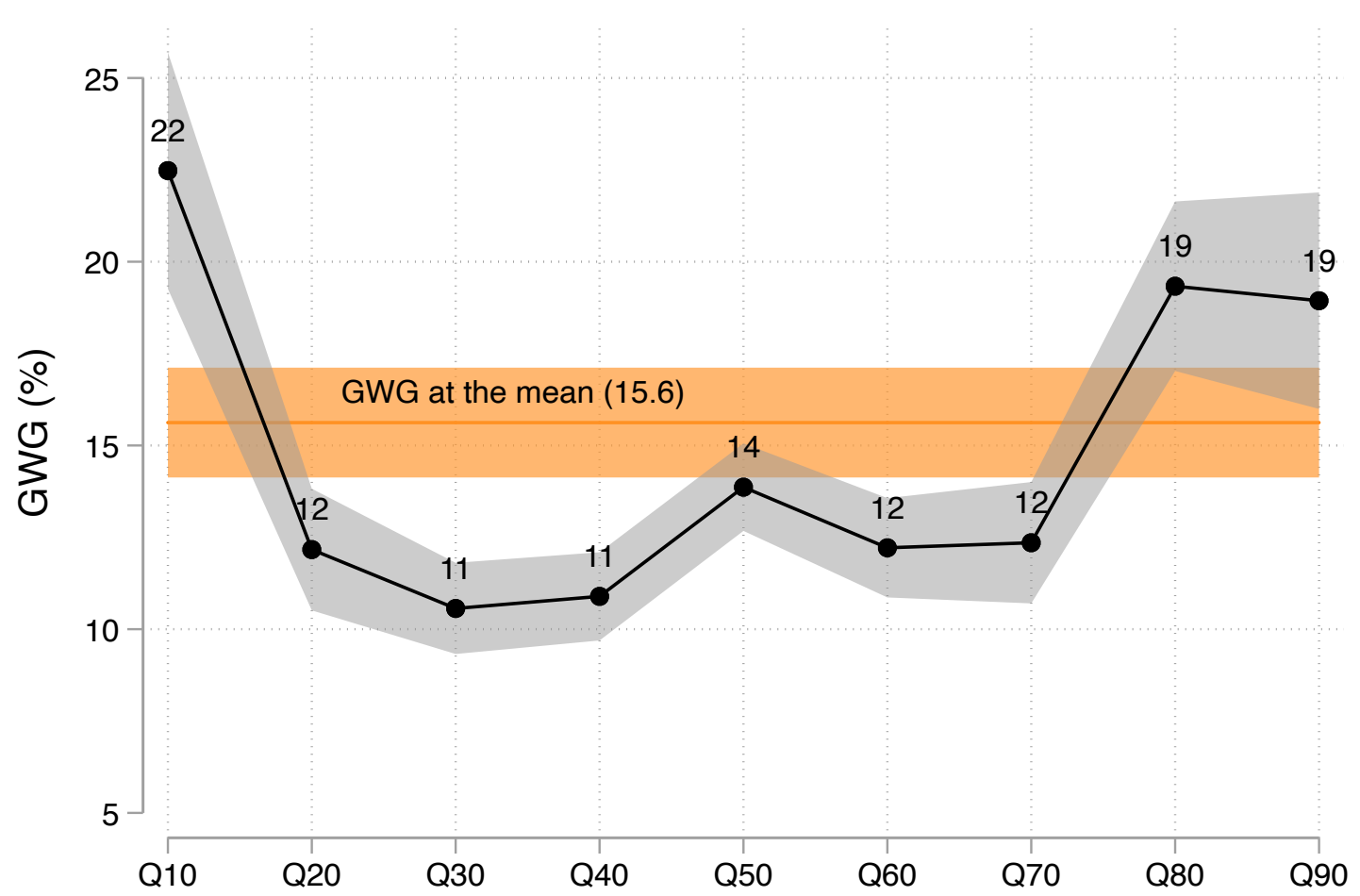

Figure 1. Raw gender wage gap ( $\%$ change) at the mean (orange line) and along quantiles (connected black dots) of the unconditional distribution of monthly wages.

Note: women's wage penalty as a percentage change compared to men. 

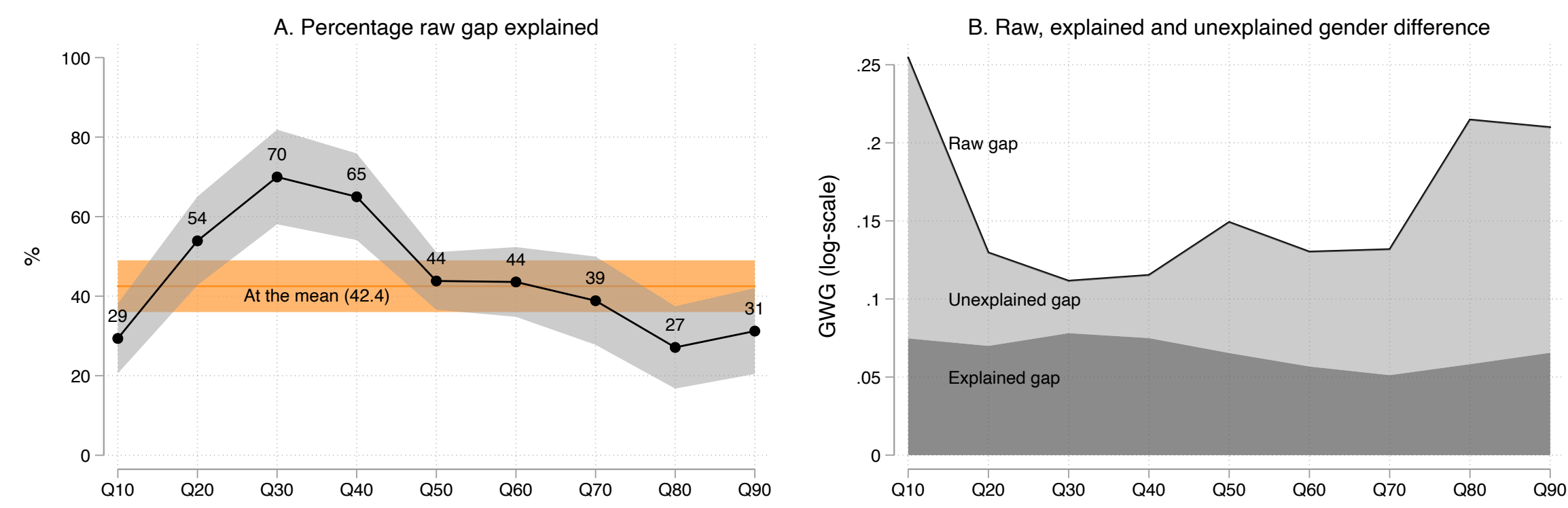

Figure 2. Panel A: Overall percentage of the raw gender gap explained at the mean (orange line) and along quantiles (connected black dots) of the unconditional wage distribution (95\% confidence intervals calculated using the Delta method). Panel B: Raw, explained and unexplained difference between men's and women's wages along quantiles of the distribution. 

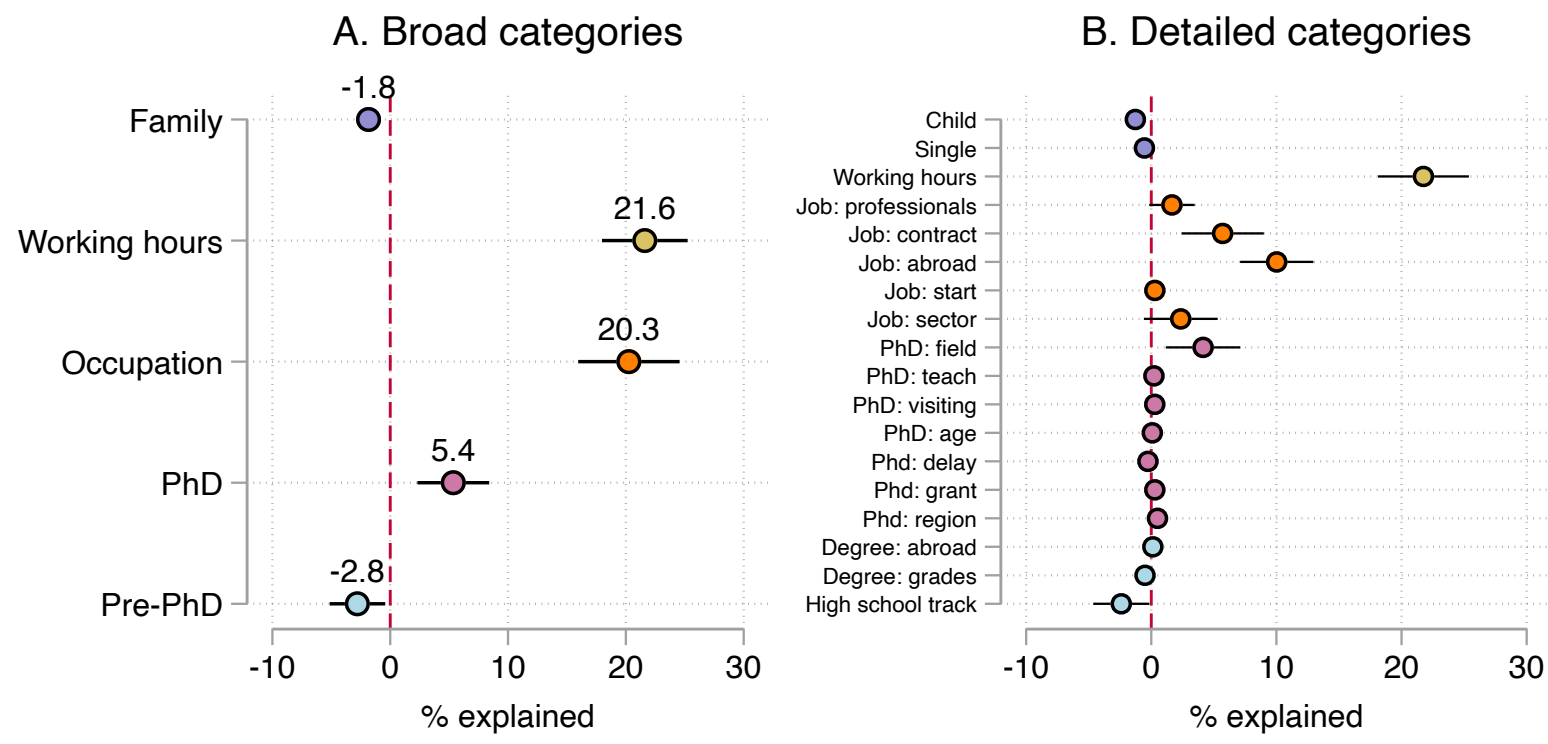

Figure 3. Percentage of the raw gender gap at the mean explained by endowments: broad and detailed categories. 


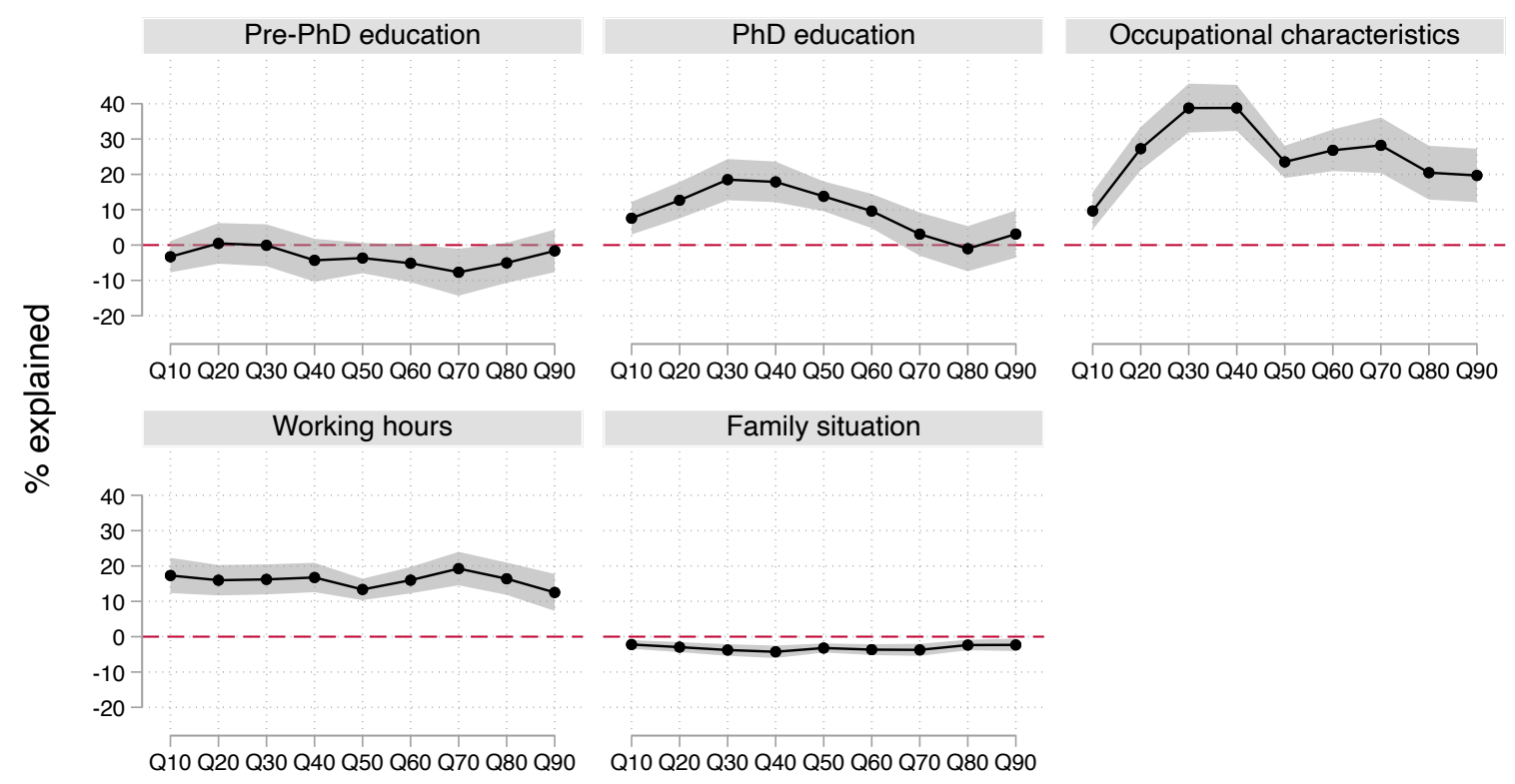

Figure 4. Percentage of the raw gender gap along the wage distribution explained by endowments: broad categories. 


\section{REFERENCES}

Ackers L and N Gill (2008). Moving People and Knowledge: Scientific Mobility in an Enlarging European Union. Cheltenham, UK: Edward Elgar.

Argentin G, Ballarino G and S Colombo (2012). Accesso ed esiti occupazionali a breve del dottorato di ricerca in Italia. Un'analisi dei dati Istat e Stella. Sociologia del Lavoro, $126,165-181$.

Arulampalam W, Booth A and Bryan M (2007). Is there a glass ceiling over Europe? Exploring the gender pay gap across the wages distribution. Industrial \& Labor Relations Review 60: 163-86.

Atkinson AB, Casarico A and S Voitchovsky (2018). Top incomes and the gender divide. The Journal of Economic Inequality, 16(2), 225-256.

Ballarino G and M Bratti (2009). Field of study and university graduates' early employment outcomes in Italy during 1995-2004. Labour, 23(3), 421-457.

Ballarino G and S Colombo (2010). Occupational outcomes of $\mathrm{PhD}$ graduates in Northern Italy. Italian Journal of Sociology of Education, 2, 149-171.

Beck EM, Horan PM and CM Tolbert, (1978). Stratification in a Dual Economy: A Sectoral Model of Earnings Determination. American Sociological Review, 43, 704-720.

Bergmann B (1974). Occupational segregation, wages and profits when employers discriminate by race or sex. Eastern Economic Journal 1: 103-10.

Bertrand M, Goldin C, and LF Katz. 2010. Dynamics of the gender gap for young professionals in the financial and corporate sectors. American Economic Journal: Applied Economics 2(3): 228-255.

Bielby W and J Baron (1986). Men and women at work - sex segregation and statistical discrimination. American Journal of Sociology 91: 759-99.

Bjerk D (2008). Glass ceilings or sticky floors? Statistical discrimination in a dynamic model of hiring and promotion. The Economic Journal, 118(530), 961-982.

Blau FD and LM Kahn (2006). The U.S. Gender Pay Gap in the 1990s: Slowing Convergence. Industrial and Labor Relations Review 60(1): 45-66.

Blau FD and LM Kahn (2017). The gender wage gap: Extent, trends, and explanations. Journal of Economic Literature, 55(3), 789-865.

Blossfeld H.-P. et al. (2015). Gender differences at labor market entry - the effect of changing educational pathways and institutional structures, in H.-P. Blossfeld, S. 
Buchholz, J. Skopek, M. Triventi (Eds.), Gender, Education and Employment: An International Comparison of School-to-Work Transitions, Cheltenham, UK: Edward Elgar, pp. 3-35.

Boll C, Jahn M and A Lagemann (2017). The gender lifetime earnings gap: Exploring gendered pay from the life course perspective (No. 179). HWWI Research Paper.

Booth AL, Francesconi M and J Frank (2003). A sticky floors model of promotion, pay, and gender. European Economic Review. 47 (2): 295-322.

Boll C, Rossen A and A Wolf (2017). The EU gender earnings gap: Job segregation and working time as driving factors. Jahrbücher für Nationalökonomie und Statistik, 237(5), 407-452.

Buchmann C, DiPrete TA and A McDaniel (2008). Gender inequalities in education. Annual review of sociology, 34, 319-337.

Campostrini S (2011). After the PhD: a study of career paths, job and training satisfaction among $\mathrm{PhD}$ graduates from an Italian university. In M Attanasio \& V Capursi (Eds.), Statistical Methods for the Evaluation of University Systems (pp. 209-222). Heidelberg: Physica.

D'Agostino A and G Ghellini (2011). Labour market outcomes for Ph.D graduates. In M Attanasio \& V Capursi (Eds.), Statistical Methods for the Evaluation of University Systems (pp. 209-222). Heidelberg: Physica.

De la Rica S, Dolado JJ and V Llorens (2008). Ceilings or floors? Gender wage gaps by education in Spain. Journal of Population Economics, 21(3), 751-776.

Chang ML (2000). The Evolution of Sex Segregation Regimes. American Journal of Sociology, 105 (6), 1658-701.

Charles, M. (1992). Cross-National Variation in Occupational Sex Segregation. American Sociological Review, 57 (4): 483-502.

Charles M and K. Bradley (2002). Equal but separate? A cross-national study of sexsegregation in higher education. American Sociological Review, 67, 573-99.

Charles M and DM Grusky (2004). Occupational Ghettos: The Worldwide Segregation of Women and Men. Stanford, CA: Stanford University Press.

Christofides LN, Polycarpou A and K Vrachimis (2013). Gender wage gaps, 'sticky floors' and 'glass ceilings' in Europe. Labour Economics, 21, 86-102.

Cohen PN and ML Huffman (2007). Working for the woman? Female managers and the gender wage gap. American Sociological Review, 72(5), 681-704. 
Crompton R and Lyonette C (2006). Work-life 'balance' in Europe. Acta Sociologica 49: 379-93.

Diamond A, Ball C, Vorley T, Hughes T, Moreton R, Howe P and T Nathwani (2014). The impact of doctoral careers. Final Report, CFE Research, Leicester.

Di Cintio M and E Grassi (2017). International mobility and wages: an analysis of Italian Ph.D. graduates. The Annals of Regional Science, 59(3), 759-791.

England P (1992). Comparable Worth: Theories and Evidence. New York: Aldine de Gruyter.

Fagan C (2001). Time, money and the gender order: work orientations and working-time preferences in Britain. Gender, Work and Organization 8: 239-66.

García-Aracil A (2007). Gender earnings gap among young European higher education graduates. Higher Education, 53(4), 431-455.

Garcia-Quevedo J, Mas-Verdú F and J Polo-Otero (2012). Which firms want PhDs? An analysis of the determinants of the demand. Higher Education, 63(5), 607-620.

Gash V (2008). Preference or constraint? Part-time workers' transitions in Denmark, France and the United Kingdom. Work, Employment and Society 22: 655-74.

Gerber TP and SY Cheung (2008). Horizontal Stratification in Postsecondary Education: Forms, Explanations, and Implications. Annual Review of Sociology, 34, 299-318.

Goldin C (2002). A Pollution Theory of Discrimination: Male and Female Differences in Occupations and Earnings. National Bureau of Economic Research, Working Paper No. 8985.

Ginn J, Arber S, Brannen J, Dale A, Dex S, Elias P, Moss P, Pahl J, Roberts C and J Rubery (1996). Feminist fallacies: a reply to Hakim on women's employment. British Journal of Sociology 47: 167-74.

Iceland J and Redstone I (2020). The declining earnings gap between young women and men in the United States, 1979-2018. Social Science Research, 92, 102479.

Jacobs JA (1996). Gender Inequality and Higher Education. Annual Review of Sociology, $22(1), 153-85$.

Jann B (2008) The Blinder-Oaxaca decomposition for linear regression models. Stata Journal, 8(4):453-479

Joy L (2003) Salaries of recent male and female college graduates: educational and labor market effects. Industrial Labor Relations Review 56: 600-21. 
Hakim C (1996). Key issues in women's work: Female heterogeneity and the polarisation of women's employment (Vol. 4). Cambridge: University of Cambridge Press.

Hakim C (2006). Women, careers, and work-life preferences. British Journal of Guidance \& Counselling, 34 (3), 279-94.

Halaby CN (2003). Where job values come from: family and schooling background, cognitive ability, and gender. American Sociological Review 68: 251-78.

Hout M (1988). More universalism less structural mobility: The American occupational structure in the 1980. American Journal of Sociology, 93, 1358-1400.

Kunze A (2018). The gender wage gap in developed countries. The Oxford Handbook of Women and the Economy, 369.

Leicht K (2008). Broken Down by Race and Gender? Sociological Explanations of New Sources of Earnings Inequality. Annual Review of Sociology, 34, 237-55.

Leontaridi M (1998). Segmented labour markets: theory and evidence. Journal of Economic Surveys, 12(1), 103-109.

Levanon A and DB Grusky (2016). The persistence of extreme gender segregation in the twenty-first century. American Journal of Sociology, 122(2), 573-619.

Mandel H (2012). Winners and Losers: The Consequences of Welfare State Policies for Gender Wage Inequality. European Sociological Review, 28 (2), 241-62.

Mandel H and M Semyonov (2006). A Welfare State Paradox: State Interventions and Women's Employment Opportunities in 22 Countries. American Journal of Sociology, $111(6), 1910-49$.

OECD (2019). Education at a Glance, Organization for Economic Cooperation and Development, Paris.

Olivetti C and B Petrongolo (2008). Unequal pay or unequal employment? A cross-country analysis of gender gaps. Journal of Labor Economics, 26(4), 621-654.

Passaretta G, Trivellato P and M Triventi (2019). Between academia and labor market. The occupational outcomes of $\mathrm{PhD}$ graduates in a period of academic reforms and economic crisis. Higher Education, 77:541-559.

Petersen P and Morgan LA (1995). Separate and unequal: occupation-establishment sex segregation and the gender wage gap. American Journal of Sociology 101: 329-65.

Phelps ES (1972). The statistical theory of racism and sexism. American Economic Review, $62(4), 659-61$. 
Posselt JR and Grodsky E (2017). Graduate education and social stratification. Annual Review of Sociology, 43, 353-378.

Reimer D, Noelke C and A Kucel (2008). Labor Market Effects of Field of Study in Comparative Perspective An Analysis of 22 European Countries. International Journal of Comparative Sociology, 49 (4-5), 233-56.

Reskin B. (1993). Sex segregation in the workplace. Annual Review of Sociology, 19, 24170.

Rios-Avila, F. (2020). Recentered influence functions (RIFs) in Stata: RIF regression and RIF decomposition. The Stata Journal, 20(1), 51-94.

Smyth E and Steinmetz S (2008). Fields of Study and Gender Segregation in European Labour Markets. International Journal of Comparative Sociology, 49 (4-5), 257-81.

Tam T (1997). Sex segregation and occupational gender inequality in the United States: devaluation or specialized training? American Journal of Sociology 102: 1652-92.

Torche F (2018). Intergenerational mobility at the top of the educational distribution. Sociology of Education, 91(4), 266-289.

Treiman DJ (1970). Industrialization and social stratification. In E. O. Laumann (Ed.), Social stratification: Research and theory for the 1970s (pp. 207-234). Indianapolis: Bobbs-Merrill Company.

Triventi M (2010). Something Changes, Something Not. Long-term Trends in Gender Segregation of Fields of Study in Italy, Italian Journal of Sociology of Education, 5 (2), pp. $47-80$.

Triventi M (2013). The gender wage gap and its institutional context: a comparative analysis of European graduates. Work, Employment and Society, 27(4), 563-580.

Weichselbaumer D, \& Winter-Ebmer, R (2005). A meta-analysis of the international gender wage gap. Journal of Economic Surveys, 19(3), 479-511. 


\section{SUPPLEMENTARY MATERIAL (ONLINE)}

\section{A. MisSINGNESS ON MONTHLY WAGES AND WEIGHTING}

We adopted a careful weighting strategy to account for selective missingness on monthly wages (among employed PhDs). Gender differences in the probability of reporting monthly wages would indeed result in biased estimates of the true gender wage gap in the population of interests. We tacked possible selection into missingness via inverse probability weighting. In a nutshell, the procedure assigns higher weights in the estimation to those individuals with a higher probability of being missing on wages. The procedure below is applied separately in two survey rounds.

The individual weight $W M_{i}$ is computed as the inverse of the response rates $(R R)$ of the groups defined by quintiles $\left(Q_{j}\right)$ of the distribution of the predicted conditional probabilities of being non-missing on wages given employment, calculated separately in each survey $s\left(p_{i s \mid E,} x\right)$ :

$$
\left(W M_{i}=\frac{1}{R R_{Q_{J}}\left(p_{i s \mid E, X}\right)}\right) \quad \text { for } j=1,2,3,4,5
$$

We use the actual response rates of the groups defined by quintiles in order to avoid extreme weighting factors due to very low or high predicted probabilities. This procedure is known as response propensity score stratification and is robust to potential misspecification of the weighting model (Chen et al. 2012). The survey-specific conditional probabilities $\left(p_{i s \mid E, X}\right)$ are predicted from the following logistic models estimated on individuals who are non-missing on all other analytical variables:

$$
\operatorname{logit}\left(p_{i s \mid E}\right)=\alpha_{t}+b_{1 s} \text { Gender }_{i}+b_{2 s} O_{i}+b_{3 s} P_{i}+b_{4 s} F_{i}+b_{5 s} M_{i}+e_{i s}
$$

Where, in addition to the gender, the predictors include social origin $(O)$, place of work $(P)$, the detailed field of study at $\mathrm{PhD}$ level $(F)$, and the macro-region of $\mathrm{PhD}$ attainment $(M)$.

Weights $W M_{i}$ are eventually combined with weighting factors provided in the surveys $\left(W R_{i}\right)$ and adjusting for non-response to the interview invitation (obtained via poststratification based on known marginal distribution of year and University of $\mathrm{PhD}$ attainment, 
citizenship, detailed field of study, and gender) to give the final individual weights $W_{i}$ used in the estimation of the gender wage gap:

$$
\left(W_{i}=W R_{i} * W M_{i}\right)
$$




\section{B. SUPPLEMENTARY TABLES}

Table B1. Percentage of truncated wages (upper and lower tail) in our analytical sample $(\mathrm{N}=10,682)$ by gender, $\mathrm{PhD}$ cohort, place of work, and Macro region of $\mathrm{PhD}$ attainment.

\begin{tabular}{|c|c|c|c|}
\hline & Non-trunc. & $\begin{array}{l}\text { Trunc. } \\
\text { upper }\end{array}$ & $\begin{array}{l}\text { Trunc. } \\
\text { lower }\end{array}$ \\
\hline & \multicolumn{3}{|c|}{ Gender } \\
\hline Men & 96.2 & 1.9 & 1.9 \\
\hline \multirow[t]{2}{*}{ Women } & 95.7 & 0.9 & 3.4 \\
\hline & \multicolumn{3}{|c|}{ PhD cohort } \\
\hline 2004 & 97.2 & 0.3 & 2.6 \\
\hline \multirow[t]{2}{*}{2008} & 95.1 & 2.1 & 2.8 \\
\hline & \multicolumn{3}{|c|}{ Work abroad } \\
\hline Abroad & 86.6 & 11.2 & 2.14 \\
\hline \multirow[t]{2}{*}{ Italy } & 96.0 & 0.5 & 3.6 \\
\hline & \multicolumn{3}{|c|}{ Macro region } \\
\hline North-west & 96.2 & 1.6 & 2.2 \\
\hline North-east & 94.2 & 2.4 & 3.4 \\
\hline Centre & 94.7 & 1.6 & 3.6 \\
\hline South & 94.6 & 0.9 & 4.6 \\
\hline Total & 96.0 & 1.3 & 2.7 \\
\hline
\end{tabular}


Table B2. Gender-endowments associations and average (log)wage by endowments.

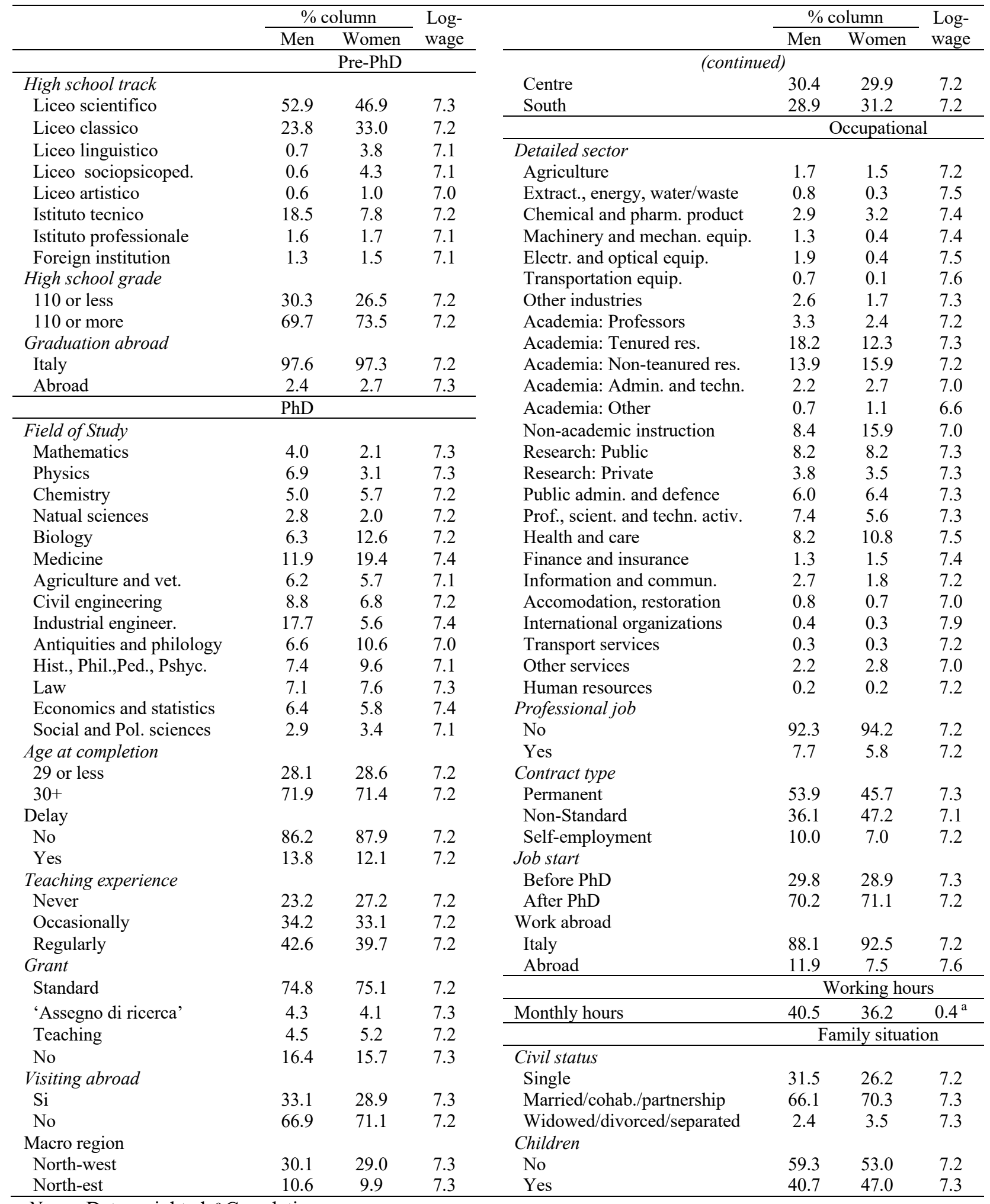

Notes: Data weighted. ${ }^{\text {a }}$ Correlation. 


\section{SUPPLEMENTARY FIGURES}
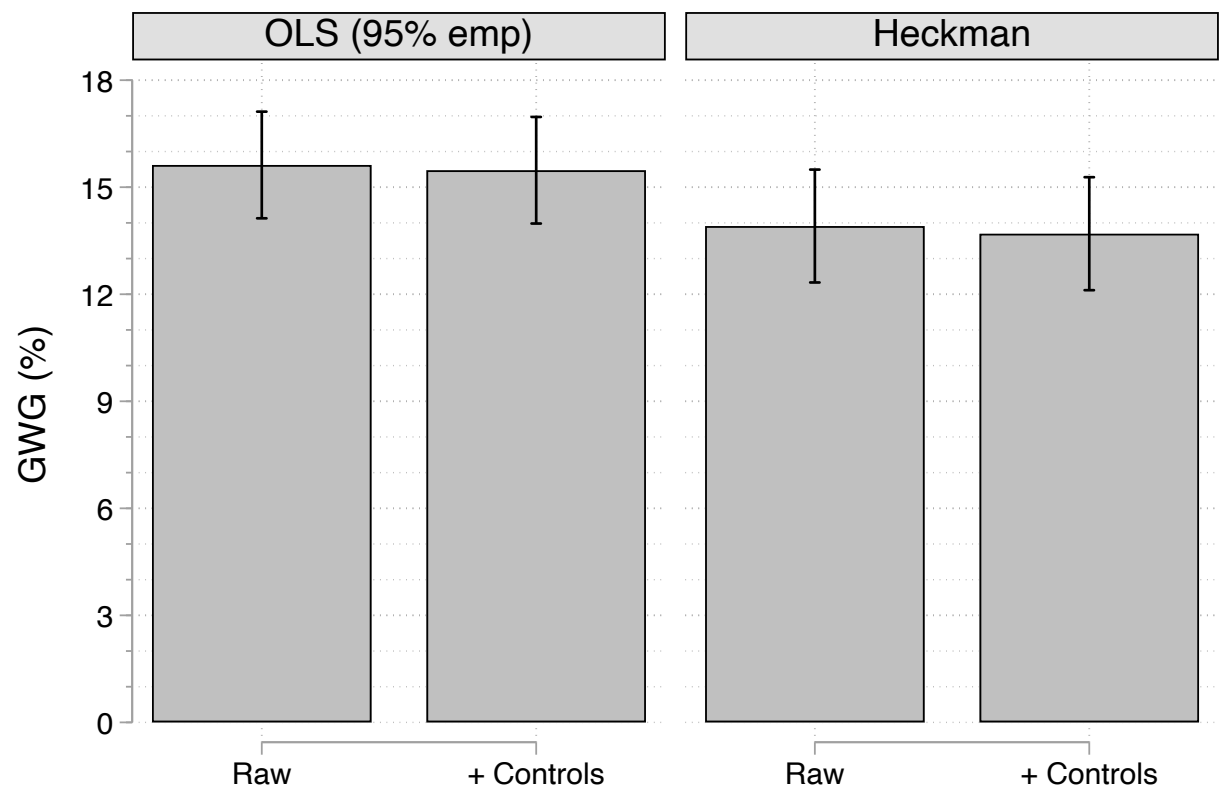

Figure C1. Raw and adjusted gender wage gaps: OLS vs Heckman selection models. Note: women's wage penalty as a percentage difference compared to men 